\title{
Releasing the Brakes in Cancer
}

\section{Shweta Dubey ${ }^{1 *}$ and Ankita Garg ${ }^{2 *}$}

${ }^{1}$ Amity Institute of Virology \& Immunology, Amity University, Uttar Pradesh, India

${ }^{2}$ University of California San Diego, La Jolla, California 92093-0672, USA

\begin{abstract}
Cancer is a heterogeneous group of diseases where abnormal cell growth with potential to invade other body parts takes control of normal homeostasis and becomes fatal if not timely and rightly treated. There are more than 100 types of cancers characterized so far and many yet to be identified. World Health Organization estimates, that worldwide in 2012 there were 4 million new cancer cases and 8.2 million cancer related deaths. Amongst various treatment options available for cancer, immunotherapy offers an approach where the focus is on enhancing or even inducing an antitumor immune response. Induction or enhancement of anti-tumor immune response is a formidable challenge in cancer because tumor cells use multiple immune evasion strategies and avoid being detected or eliminated by immune cells. Immune checkpoints refer to a network of stimulatory or inhibitory signaling pathways in the immune system which are critical in maintaining self-tolerance, limiting tissue damage and modulating the quality of immune response. Substantial evidence indicates that up regulation of inhibitory signaling molecules (CTLA-4, PD-1) by tumor cells subvert activation of tumor antigen specific Teffector cells. Therefore, blockade of inhibitory signaling pathways may be one potential way of revitalizing an exhausted immune response in tumors. Using this approach, antibodies directed against CTLA-4 and PD-1 have been shown an acceptable therapeutic benefit in preclinical models and cancer patients. This review will discuss the important immune checkpoints that have been identified critical to suppress anti-tumor immunity and have been exploited as drug targets.
\end{abstract}

\section{Keywords: Cancer stem cells; Anti-tumor; Lymphatic}

Tumors develop as a result of uncontrolled cell growth, avoiding programmed cell death and often bypassing the signals generated to restrict cell division [1]. During this uncontrolled growth, cancer cells undergo profound cellular and molecular changes forming a complex niche known as the Tumor microenvironment (TME), which comprises of cells of tumor origin with genetic alterations and genetically unaltered non-malignant cells such as fibroblasts, endothelial cells (blood and lymphatic), mesenchymal cells and components of extracellular matrix [2]. It is now evident that the stromal structure is critical for tumor sustenance and it creates a pathway for infiltration of various immune cell types like natural killer cells (NK), macrophages, activated T-cells, tumor associated macrophages (TAM) and myeloid derived suppressor cells (MDSC). Since the formulation of "immune surveillance" hypothesis at the beginning of $20^{\text {th }}$ century by Paul Ehrlich and later refined by Burnet and Thomas in 1950's, immune cells particularly lymphocytes and NK cells have been established as critical for detection and destruction of tumor cells [3].

According to the concept of cancer "immune editing", immune selection favors the emergence of tumor variants that have accumulated antigenic alterations sufficient for the evasion of immune surveillance mechanisms leading to tumor progression [4]. Even though the down regulation of MHC I on tumor cells invoke a robust NK cell activity leading to tumor cell lysis, T-cells are critical to control tumor cell expansion. A concerted interaction between both innate and adaptive immune system is important for elimination of cancer cells [5]. Appropriate cues from a prior innate immune response influence $\mathrm{T}$ cell differentiation i.e. innate signals from cells like classically activated macrophages and dendritic cells induce activation of cytotoxic $\mathrm{T}$ cells (CTLs) and T helper (TH1) cells which is beneficial to the host in eliminating tumor cells [6]. On contrary, signals generated from alternatively activated macrophages (AAM) or myeloid derived suppressor cells (MDSC) [7,8] promote tumor metastasis and progression (Figure 1). Clinical manifestations of cancer may be visible once the immune response skews to promote tumor progression. Immunotherapy augments anti-tumor immune response by rewiring host immune response from tumor progression to tumor elimination (Figure 1).

\section{Regulation of T Cell Responses}

Both CTL and Th1 cells are crucial for an effective anti-tumor immune response. Being important mediators of anti-tumor immunity, $\mathrm{T}$ cells are most favored targets for translational development of immunotherapeutic molecules. A variety of tumor specific (TS)

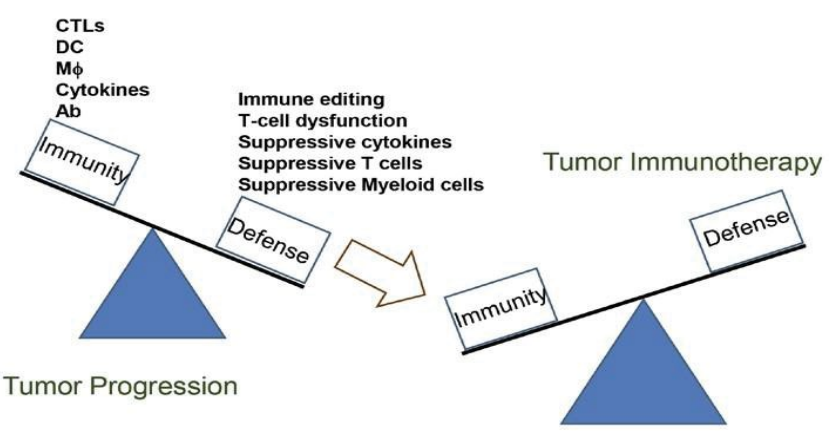

Figure 1: The self-defense of tumors overweighs the anti-tumor immunity leading to clinical manifestations of cancer. The various immunotherapeutic approaches are adopted to reverse this imbalance.

*Corresponding authors: Ankita Garg, University of California San Diego, 9500 Gilman Drive, La Jolla, CA 92093-0672, USA, Tel: 858534 7474; Fax: 858534 7411; E-mail: ajaiswal@ucsd.edu

Shweta Dubey, Amity Institute of Virology and Immunology, Amity University, Uttar Pradesh, India, Tel: 0120-2445252/4713600; E-mail: sdubey@amity.edu

Received March 16, 2016; Accepted April 04, 2016; Published April 11, 2016

Citation: Dubey S, Garg A (2016) Releasing the Brakes in Cancer. J Bioanal Biomed 8: 017-022. doi:10.4172/1948-593X.1000147

Copyright: (C) 2016 Dubey S, et al. This is an open-access article distributed under the terms of the Creative Commons Attribution License, which permits unrestricted use, distribution, and reproduction in any medium, provided the original author and source are credited. 
or tumor associated (TA) antigens derived from oncogenic viruses (HPV, SV40), differentiation antigens (Tyrosinase, Carcinoembryonic antigens, Alpha-fetoprotein, prostate-specific antigen), epigenetically regulated antigens (cancer antigen-1, MAGE-antigens) and neoantigens allow T cells to distinguish between normal and transformed cell $[9,10]$. Induction of effector $\mathrm{T}$ cell response is sequential, antigen specific $\mathrm{T}$ cells are first primed in the secondary lymphoid organs through the interaction with antigen presenting cells (APC). APC particularly dendritic cells (DC) sample antigens from tumor cells and present antigens to $\mathrm{CD}^{+}{ }^{+} \mathrm{T}$ cells via the MHC class- II pathway or to $\mathrm{CD} 8{ }^{+}$ $\mathrm{T}$ - cells via cross presentation or cross priming $[11,12]$. This antigen recognition in association with MHC is insufficient to effectively activate T cells; APC provide additional cosignals that regulate the breadth of $\mathrm{T}$ cell activation. These multiple cosignals can be induced by stimulatory (CD80 / CD86: CD28) and inhibitory molecules also known as "Immune checkpoints" [13,14]. The entire process of $\mathrm{T}$ cell activation and differentiation is finely regulated by a balance between multiple stimulatory or inhibitory receptors on $\mathrm{T}$ cells and their respective ligands present on APC (Table 1). APC also provide the additional costimulatory signals, which are mandatory for $\mathrm{T}$ cell priming. After the priming phase, several factors, including but not limited to defective $\mathrm{T}$ cell recruitment at tumor site, inactivation of effector functions of primed $\mathrm{T}$ cells or induction of $\mathrm{T}$ cell apoptosis contribute to the diminished response of antigen specific $\mathrm{T}$ cells at the site of tumor development ultimately causing reduced cancer elimination.

\begin{tabular}{|c|c|c|c|}
\hline \multicolumn{2}{|l|}{ T cells } & APCs / Tumor cells & Effect \\
\hline \multicolumn{4}{|c|}{ Immunoglobulin family } \\
\hline \multicolumn{2}{|l|}{ CD28 } & B7.1/B7.2 & + \\
\hline \multicolumn{2}{|l|}{ ICOS } & ICOS-L & + \\
\hline \multicolumn{2}{|l|}{ CTLA-4 } & B7.1/B7.2 & - \\
\hline \multicolumn{2}{|l|}{ PD-1 } & PDL-1 / PDL-2 & - \\
\hline \multicolumn{2}{|l|}{$?$} & $\mathrm{~B} 7-\mathrm{H} 3$ & - \\
\hline \multicolumn{2}{|l|}{$?$} & $\mathrm{~B} 7-\mathrm{H} 4$ & - \\
\hline \multicolumn{2}{|l|}{ BTLA } & HVEM & - \\
\hline \multicolumn{2}{|l|}{ LAG-3 } & MHC-II & - \\
\hline \multicolumn{2}{|l|}{ CD160 } & HVEM & - \\
\hline \multicolumn{2}{|l|}{ VISTA } & $?$ & - \\
\hline \multicolumn{4}{|l|}{ TNF-R family } \\
\hline \multicolumn{2}{|l|}{ CD4L / CD154 } & CD40 & + \\
\hline \multicolumn{2}{|l|}{$0 X-40$} & OX-40L & + \\
\hline \multicolumn{2}{|l|}{ 4-1BB } & 4-1BBL & + \\
\hline \multicolumn{2}{|l|}{ GITR } & GITR-L & + \\
\hline \multicolumn{2}{|l|}{ CD30 } & CD30L & + \\
\hline \multicolumn{2}{|l|}{ HVEM } & LIGHT & + \\
\hline \multicolumn{4}{|c|}{ T cell immunoglobulin mucin family } \\
\hline TIM-1 & $?$ & \multicolumn{2}{|l|}{+} \\
\hline TIM-2 & $?$ & \multicolumn{2}{|l|}{-} \\
\hline TIM-3 & Galactin-9 & \multicolumn{2}{|l|}{-} \\
\hline \multicolumn{4}{|c|}{ Butyrophilin family } \\
\hline BTN & BTNL & \multicolumn{2}{|l|}{-} \\
\hline
\end{tabular}

+ indicates stimulation and - indicates inhibition of T cell activation. ? Indicates receptor or ligand yet to be identified. ICOS: Inducible costimulator of T cells [67] ,CTLA-4: Cytotoxic T Lymphocyte Antigen 4 [68], PD-1: Programmed Death 1 [69], BTLA: B and T Lymphocyte Attenuator [70], LAG-3: Lymphocyte Activation Gene [71], VISTA: $V$-domain Ig Suppressor of T cell Activation [72], OX-40: CD134 [73], 4-IBB: CD137 [74], GITR: Glucocorticoid-Induced Tumornecrosis factor Receptor [75], HVEM: Herpes Virus Entry Mediator [76], TIM: T cell Immunoglubulin Mucin family [77,78], BTN: Butyrophilin [79]

Table 1: Costimulatory molecules and their corresponding ligands expressed on $T$ cells and APCs / tumor cells.
Of the various proteins that regulate $\mathrm{T}$ cell activation (Table 1), Cytotoxic T Lymphocyte Antigen-4 (CTLA-4), Programmed Death-1 (PD-1), B7 family members B7-H3, B7-H4, T cell Immunoglobulin and Mucin domain-containing protein 3 (Tim-3), and Lymphocyte Activation Gene-3 (LAG-3) block costimulation and abrogate the response of activated $\mathrm{T}$ cells (Figure 2). Abnormal expression of either of these inhibitory checkpoint molecules is a predominant immune evasion mechanism in cancers, chronic infections and autoimmune diseases. In this review, we will discuss the important immune checkpoints that have been identified critical to suppress anti-tumor immunity and have been exploited as drug targets. We will also discuss other immune check points and their antagonists in preclinical development for various cancers.

\section{CTLA-4 First Target Identified to Release Brakes}

Amongst all the therapies that have been used to potentiate immune response against cancer, immune checkpoint blockade has shown most promising results and has been appropriately heralded as a major scientific breakthrough in translational research. CTLA-4 was the first inhibitory immune checkpoint molecule to be clinically targeted to enhance T cell function. Like costimulatory CD28, CTLA-4 is also expressed on T cells; but unlike CD28, which is constitutively expressed on T cells, CTLA- 4 expression is up regulated only after T cell activation and regulates early stages of T cell activation. Both CD28 and CTLA-4 bind to CD80 / CD86 on APCs but compared to CD28, CTLA4 binds with much higher affinity. Therefore, expression of CTLA- 4 on activated T cells induces a competitive inhibition of stimulatory CD28CD80 / 86 signaling and inhibits $\mathrm{T}$ cell activation $[15,16]$. Functional studies on T cell activation suggest that crosslinking of CTLA- 4 on TCR and CD28 stimulated $\mathrm{T}$ cells resulted in an anergic phenotype similar to that obtained when T cells are TCR stimulated in the absence of costimulatory signal. Specific pathways by which CTLA- 4 suppresses $\mathrm{T}$ cell activation are still under investigation and it is suggested that activation of phosphatases downstream of CTLA-4 engagement with its ligands inhibits $\mathrm{T}$ cell activation. Critical role of CTLA4 in $\mathrm{T}$ cell activation is best evident in ctla- $4^{-/-}$mice, which exhibit a fatal lymphoproliferative and immune hyperactivation phenotype $[17,18]$. This provided convincing confirmation for blocking CTLA-4 expression and restoring function of activated $\mathrm{T}$ cells. Subsequently, various studies in human and animal models suggested that blocking CTLA-4 inhibitory signaling or "taking the brakes off" the immune cells restored $\mathrm{T}$ cell homeostasis.

Due to lethal effects in ctla- $4^{-/-}$mice and absence of tumor specific CTLA-4 expression, CTLA-4 blockade did not originally appear to be a promising therapeutic strategy for cancer. However, Allisson et al demonstrated that partial blockade with CTLA-4 blocking antibody was beneficial in elimination of tumor growth with low toxicity in mice [19]. In poorly immunogenic tumors, combination of CTLA-4 blockade with GM-CSF based tumor vaccine showed better results as compared to CTLA-4 monotherapy alone [20]. In general, combination of CTLA-4 blockade with any methods that enhanced tumor antigen presentation (DNA or peptide based vaccines) yielded better results in many preclinical studies $[21,22]$. These preclinical observations led to the development of anti-CTLA-4 antibodies for clinical use.

Two fully humanized CTLA-4 blocking antibodies: Ipilimumab (MDX-010) and Tremelimumab (CP-675,206) are presently under clinical investigation. Ipilimumab was approved in 2011 at a dose of $3 \mathrm{mg} / \mathrm{kg}$ for treatment of un-resectable or metastatic melanoma by regulatory agencies in the United States and Europe [23]. Tremelimumab has been granted orphan drug status by FDA for treatment of malignant 


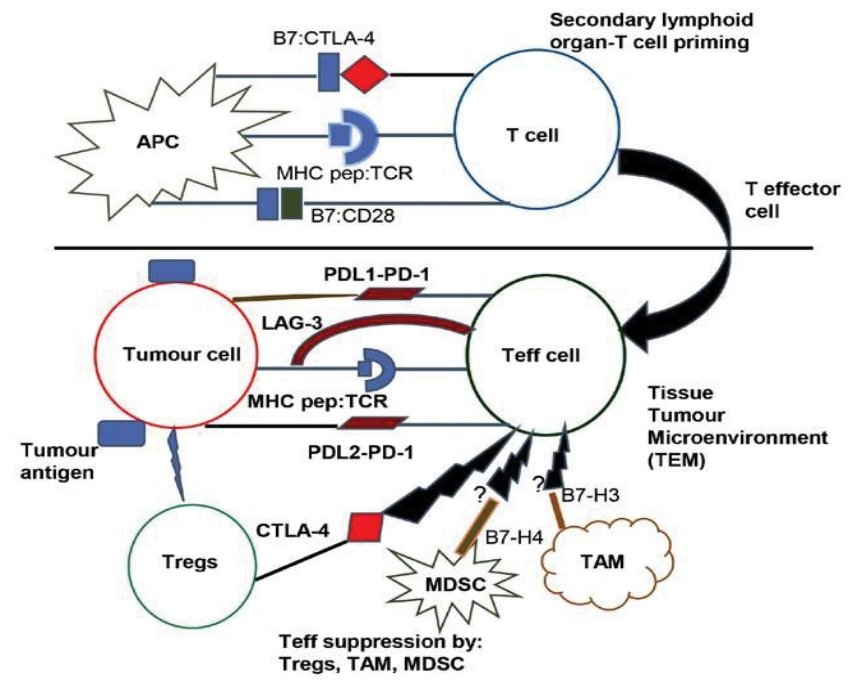

Figure 2: CTLA-4 and PD-1 in regulation of anti-tumor $T$ cell responses: (Upper Panel) Tumor antigen in the lymph nodes are presented by antigen presenting cells (APCs) via MHC to TCR which primes the T cell. APCs express ligands B7 which bind to the CD28 on T cells and enhances T cell activation. Activated T cells express CTLA-4 which also binds to CD28 but with much higher affinity. The tumor-specific $T$ cell activation leads to proliferation and generation of $\mathrm{T}$ effector cells (Teff) which also express PD-1. (Lower Panel) PD- $1^{+}$Teff cells after trafficking to tumor microenvironment (TEM) encounter PD-1 ligands expressing tumor cells, which inhibit killing function of Teff cells. Thus, CTLA - 4 and PD-1 pathways are complementary to regulate antitumor Teff cells. Other suppressive cell types induced from TEM such as tumor associated macrophages (TAM), myeloid derived suppressor cells (MDSC), $\mathrm{T}$ regulatory cells (Tregs), further contribute to inhibit T cell response at site of tumor formation.

mesothelioma. Both antibodies have produced a good therapeutic response accompanied by immune related adverse events in treated patients [24]. Besides humanized monoclonal antibodies, CTLA-4 Ig fusion proteins (Abatacept, Belatacept) have also shown potent immunosuppressive properties in animal models of transplantation and autoimmunity [25-27]. CTLA-4 Ig is an approved therapy for rheumatoid arthritis $[28,29]$ and clinical trials are currently in progress to assess its efficacy in transplantation tolerance, psoriasis and Crohn's disease.

Though CTLA- 4 blockade proved to be beneficial only in a subset of cancer patients, yet it represented a giant leap for tumor immunotherapy. The adverse effects associated with CTLA - 4 blockade were as expected because blocking immune regulatory molecules can predispose the host to autoimmunity and hyper active immune responses. Interestingly, an important adverse immune event observed in patients of melanoma treated with CTLA-4 antibodies is development of antibodies against gut bacteria [30,31]. The correlates of immune protection or predictors of response after CTLA- 4 blockade need to be clearly defined so that individual patients could be selected for CTLA- 4 blockade.

\section{PD-1 Pathway Blockade}

The success of anti - CTLA-4 revolutionized the concept of targeting immune checkpoints to enhance anti -tumor activity. Another important inhibitory immune checkpoint molecule involved in regulation of T cell responses is PD-1 / PDL-1.PD-L2 pathway [32]. PD-1 belongs to CD28 family of immunoreceptors and is expressed on activated $\mathrm{B}, \mathrm{T}$ and myeloid cells and tumor infiltrating lymphocytes. The two PD-1 ligands have differential expression; PD-L1 (also called B7H-1) is expressed on T cells, B cells, macrophages and DC and is up regulated following activation of these cells $[33,34]$. In contrast, PD-L2 (also called B7-DC) expression is inducible on DC and macrophages [35].

Though the exact function of these ligands still needs to be elucidated, available data suggests that ligation of PD -1 to PD-L1 or PDL2 triggers an inhibitory signaling pathway in the PD-1 expressing cells inhibiting $\mathrm{T}$ cell proliferation, cytokine production, and cell adhesion $[33,36]$. Similar to other CD28 family members, PD-1 transduces an inhibitory signal only when engaged in combination with $\mathrm{T}$ cell receptor (TCR) ligation, but not when cross-linked on its own. Both CTLA- 4 and PD-1 have inhibitory effects on T cell activation however the timing of inhibition and signaling pathways differ for both the molecules. It is suggested that CTLA- 4 inhibits immune responses in lymph node (during T cell priming phase) while PD-1 acts late at tissue sites (during the $\mathrm{T}$ cell effector phase) to limit $\mathrm{T}$ cell activation and avoid collateral damage [37]. Crucial role for PD-1 signaling has been best described in many models of chronic viral infection where exhausted $\mathrm{T}$ cells expressed high levels of PD-1 accounting for T cell dysfunction in chronic infection $[38,39]$. Similar to chronic infections, a comparable scenario of chronic antigen exposure in tumor microenvironment induces PD-1 / PD-L1 / PD-L2 expression in tumor cells leading to $\mathrm{T}$ cell exhaustion [40-43]. PD-1 expression was reported on tumor infiltrating lymphocytes and ligands for PD-1 were expressed on tumor cells of epithelial, non- epithelial and haematopoetic origin (Figure 2) [44]. Therefore, PD-1 signaling is an important pathway that induces impairment of $\mathrm{T}$ cell response in tumors and blocking this pathway could potentially liberate the T cells to perform effector functions [45].

A number of therapeutic antibodies that disrupt the PD-1 axis have entered clinical development. Although the various antibodies differ in structure, they can be broadly classified into two categories i) those that target PD -1(Nivolumab, Pidilumumab, MK3475 [46-48], ii) those that target PD-L1 (MPDL3280A; MEDI4736,; BMS-936559, MSB0010718C) [49-51],AMP-224 (Amplimmune). AMP-224 is a PD$\mathrm{L} 2 \mathrm{Fc}$ fusion protein that is hypothesized to induce depletion of PD-1 positive T-cells representing exhausted effector cells.

Initial results with PD-1 blockade indicate a lower toxicity profile as compared to CTLA-4 blockade [52]. Certain immune related adverse events have also been described for patients treated with PD-1 and PD-L1 antibodies [52,53]. Overall, single agents have shown a modest response in tumor regression or improving overall survival. Since the nexus between tumor cells and immune system operates at multiple levels, combinatorial immunotherapy may be essential to break evasion mechanisms at multiple checkpoints. Combined immunotherapy with both CTLA- 4 and PD-1 blockade in patients with melanoma has shown an accepted safety profile and better clinical activity as compared to monotherapy [54]. Recent data has also suggested that blocking CTLA4 and PD-1 enhances anti-tumor response by ablating T regulatory cells $[55,56]$

\section{Beyond CTLA-4 and PD-1 Pathway}

Deciphering the basic mechanisms of T cell regulation in tolerance, inflammation and chronic infections has contributed to better understanding of other immune-checkpoints that are increasingly being characterized as targets for releasing the $\mathrm{T}$ cell brakes in cancer. As a result, the spectrum of immune-checkpoint targets is expanding beyond inhibitory receptors discussed above; numerous inhibitory ligands belonging to B7-family but with unknown receptors (B7-H3 and B7-H4) have been identified on tumor or tumor infiltrating cells and blockade of these in mouse models enhances anti-tumor immunity 


\begin{tabular}{|l|l|l|}
\hline Antibody & Molecule & Development Stage \\
\hline Nivolumab & Fully Hu-lgG4 & US approved: Advanced $\quad$ Melanoma, \\
\hline Pembrolizumab & Humanized IgG4 & Ph III (RCC, HNSCC, GBM, Gastric) \\
\hline & & US Approved: Advanced \\
\hline Pidilizumab & Humanized IgG4 & Ph II multiple tumors (Pancreatic, CRC, RCC, Prostate, CNS) \\
\hline AMP-224 & Fc - PD-L2-Fusion & Ph I \\
\hline MPDL3280A & Engineered Hu IgG1 & Ph III \\
\hline MSB0010718C & Fully Hu IgG1 & Ph III \\
\hline
\end{tabular}

Table 2A: Clinical Development of Anti-PD-1 Checkpoint Inhibitors.

\begin{tabular}{|c|c|c|c|}
\hline Target & Antibody & Molecule & Development \\
\hline \multirow{3}{*}{ CTLA-4 } & Ipilimumab & Humanized IgG1 & $\begin{array}{l}\text { Approved: Advanced Melanoma, } \\
\text { Ph III (RCC, NSCC, GBM, SCLC) }\end{array}$ \\
\hline & Tremelimumab & Fully Hu lgG2 & Ph III (NSCLC, HNSCC) \\
\hline & INCB024360 & Molecule Inhibitor & $\mathrm{Ph} \mathrm{I}$ \\
\hline \multirow{2}{*}{ IDO } & NLG919 & Small Molecule Inhibitor & $\mathrm{Ph} \mathrm{I}$ \\
\hline & MDX-1105 & Fully Hu lgG4 & $\mathrm{Ph} \mathrm{I}$ \\
\hline \multirow{2}{*}{ PD-L1 } & MEDI4736 & Engineered $\mathrm{Hu} \operatorname{lgG} 1$ & $\mathrm{Ph}$ III \\
\hline & MPDL3280A & Humanized IgG & $\mathrm{Ph}$ II; Ph III \\
\hline \multirow{2}{*}{ LAG-3 } & BMS-986016 & - & $\mathrm{Ph} \mathrm{I}$ \\
\hline & IMP321 & LAG3-Ig & Fusion protein \\
\hline \multicolumn{4}{|l|}{ Ph II (Breast cancer) } \\
\hline $\mathrm{B} 7-\mathrm{H} 3$ & MGA271 & Humanized lgG1 & $\mathrm{Ph} \mathrm{I}$ \\
\hline B7- H4 & - & - & Preclinical \\
\hline TIM-3 & - & - & Preclinical \\
\hline
\end{tabular}

NSCLC - Non small cell lung cancer; RCC - Renal cell carcinoma; HNSCC - Hean and neck squamous cell carcinoma; GBM - Glioblastoma; CRC - Colon rectum cancer; SCLC - Small cell lung cancer

Table 2B: Clinical Development of Other Checkpoint Inhibitors Target Antibody.

[57]. Another inhibitory checkpoint molecule in the same category as CTLA- 4 and PD- 1 is LAG-3, which inhibits T cell proliferation, function [58-61] and contributes to the suppressive action of T regulatory cells (Tregs) [62]. Dual blockade of both PD-1 and LAG-3 has been shown to restore tumor specific immune response and enhance survival in murine models of tumor [58]. Currently clinical trials are underway to determine the safety and efficacy of combinatorial therapy with anti-LAG-3 antibody with or without PD-1 blockade in solid tumors (trial ID CA224-020, NLM Identifier NCT01968109). Apart from immune checkpoints, metabolic checkpoints such as inhibitor compounds for enzymes like indoleamine 2,3-dioxygenase (IDO), isocitrate dehydrogenase, adenosine signaling etc are also an emerging target for development of anti-cancer therapeutic molecules [63-65]. Tumor microenvironment presents many metabolic challenges which may contribute to a rewiring of anti-tumor $\mathrm{T}$ cell response. This new area of immunometabolism will certainly add new dimensions to manipulate $\mathrm{T}$ cell function; we are already noticing an exponential information explosion in this arena as well. This may open up entirely new avenues to treat immune mediated disorders. Combination of immune checkpoints which boost the immune response and metabolic checkpoints which provide a host friendly tumor microenvironment may also be one combinatorial approach in cancer therapy.

The targets for which biological or small molecule inhibitors are currently available are detailed in the Table 2, but the list is not comprehensive. Tumor immunotherapy has seen a dramatic transition from the era of Coley's toxin [66] to immune checkpoints. Nevertheless, substantial data show that immunotherapy does not follow "one size fits all" approach and predictors of response to therapy need to be identified so that clinicians can selects patients for particular monotherapy or combination immunotherapy. Blocking a single molecule has not produced a completely curative response thus underscoring the importance of multiple, probably, redundant molecules working in tandem to promote immune escape of tumor cells. While it is possible that there are many other molecules still to be discovered there is substantial evidence to suggest that combinatorial therapy involving immune, molecular and metabolic checkpoints and not monotherapy alone might be the ideal way to develop completely curative and specific immune-therapeutic modalities.

\section{Conclusion}

Exploiting the immune system against tumor cells has been considered an attractive therapeutic option, successive failures or limitation of practical usage of various immune therapeutic approaches resulted in the loss of creditability of cancer immunotherapy. With the better understanding of $\mathrm{T}$ cell activation and regulation and its successful translation towards development of broad spectrum anticancer agents in form of immune checkpoint inhibitors has revived the immune therapy field. However, this novel treatment which engages patient's immune response to target tumor cells needs to be integrated with conventional approaches as surgery, chemotherapy, radiation therapy and targeted therapy which directly attack cancer cells. Furthermore, achieving maximum clinical benefit from immunotherapeutic molecules may also require a careful investigation of extent of cooperatively between different immune checkpoints. It might also be important to contemplate combination treatments that can augment both innate (NK cells, $\gamma \delta \mathrm{T}$ cells etc) and adaptive arm of host immune system in tumor microenvironment for better clinical benefit.

\section{References}

1. Hanahan D, Weinberg RA (2000) The hallmarks of cancer. Cell 100: 57-70. 
2. Quail DF, Joyce JA (2013) Microenvironmental regulation of tumor progression and metastasis. Nat Med 19: 1423-1437.

3. BURNET M (1957) Cancer; a biological approach I The processes of control. Br Med J 1: 779-786.

4. Dunn GP, Bruce AT, Ikeda H, Old LJ, Schreiber RD (2002) Cancer immunoediting: from immunosurveillance to tumor escape. Nat Immunol 3: 991-998.

5. Cohen S, Cohen MC (1978) Mechanisms of tumor immunity An overview. Am J Pathol 93: 449-458.

6. Hadrup S, Donia M, Thor Straten P (2013) Effector CD4 and CD8 T cells and their role in the tumor microenvironment. Cancer Microenviron 6: 123-133.

7. Gabrilovich DI, Nagaraj $S$ (2009) Myeloid-derived suppressor cells as regulators of the immune system. Nat Rev Immunol 9: 162-174.

8. Noy R, Pollard JW2 (2014) Tumor-associated macrophages: from mechanisms to therapy. Immunity 41: 49-61.

9. Vigneron N (2015) Human Tumor Antigens and Cancer Immunotherapy. Biomed Res Int 2015: 948501.

10. Coulie PG, Van den Eynde BJ2, van der Bruggen P2, Boon T3 (2014) Tumour antigens recognized by $T$ lymphocytes: at the core of cancer immunotherapy. Nat Rev Cancer 14: 135-146.

11. Diamond MS, Kinder M, Matsushita H, Mashayekhi M, Dunn GP, et al. (2011) Type I interferon is selectively required by dendritic cells for immune rejection of tumors. J Exp Med 208: 1989-2003.

12. Steinman RM, Banchereau J (2007) Taking dendritic cells into medicine. Nature 449: 419-426.

13. Topalian SL, Drake CG2, Pardoll DM3 (2015) Immune checkpoint blockade: a common denominator approach to cancer therapy. Cancer Cell 27: 450-461.

14. Pardoll D (2015) Cancer and the Immune System: Basic Concepts and Targets for Intervention. Semin Oncol 42: 523-538.

15. Boulougouris G, McLeod JD, Patel YI, Ellwood CN, Walker LS, et al. (1998) Positive and negative regulation of human $\mathrm{T}$ cell activation mediated by the CTLA-4 / CD28 ligand CD80. J Immunol 161: 3919-3924.

16. Walker LS, Sansom DM (2011) The emerging role of CTLA4 as a cell-extrinsic regulator of T cell responses. Nat Rev Immunol 11: 852-863.

17. Tivol EA, Borriello F, Schweitzer AN, Lynch WP, Bluestone JA, et al. (1995) Loss of CTLA-4 leads to massive lymphoproliferation and fatal multiorgan tissue destruction, revealing a critical negative regulatory role of CTLA-4. Immunity 3: 541-547.

18. Waterhouse P, Penninger JM, Timms E, Wakeham A, Shahinian A, et al. (1995) Lymphoproliferative disorders with early lethality in mice deficient in Ctla-4. Science 270: 985-988.

19. Leach DR, Krummel MF, Allison JP (1996) Enhancement of antitumor immunity by CTLA-4 blockade. Science 271: 1734-1736.

20. Quezada SA, Peggs KS, Curran MA, Allison JP (2006) CTLA4 blockade and GM-CSF combination immunotherapy alters the intratumor balance of effector and regulatory T cells. J Clin Invest 116: 1935-1945

21. Borchmann P, Treml JF, Hansen H, Gottstein C, Schnell R, et al. (2003) The human anti-CD30 antibody $5 \mathrm{~F} 11$ shows in vitro and in vivo activity against malignant lymphoma. Blood 102: 3737-3742.

22. Soiffer R, Hodi FS, Haluska F, Jung K, Gillessen S, et al. (2003) Vaccination with irradiated, autologous melanoma cells engineered to secrete granulocytemacrophage colony-stimulating factor by adenoviral-mediated gene transfer augments antitumor immunity in patients with metastatic melanoma. J Clin Oncol 21: 3343-3350.

23. Hodi FS, O'Day SJ, McDermott DF, Weber RW, Sosman JA, et al. (2010) Improved survival with ipilimumab in patients with metastatic melanoma. N Engl J Med 363: 711-723

24. Phan GQ, Yang JC, Sherry RM, Hwu P, Topalian SL, et al. (2003) Cancer regression and autoimmunity induced by cytotoxic $T$ lymphocyte-associated antigen 4 blockade in patients with metastatic melanoma. Proc Natl Acad Sci U S A 100: 8372-8377.

25. Larsen CP, Pearson TC, Adams AB, Tso P, Shirasugi N, et al. (2005) Rational development of LEA29Y (belatacept), a high-affinity variant of CTLA4-Ig with potent immunosuppressive properties. Am J Transplant 5: 443-453.

26. Salomon B, Bluestone JA (2001) Complexities of CD28/B7: CTLA-4 costimulatory pathways in autoimmunity and transplantation. Annu Rev Immunol 19: 225-252.

27. Dall'Era M, Davis J (2004) CTLA4Ig: a novel inhibitor of costimulation. Lupus 13: 372-376.

28. Herrero Beaumont G, Martinez Calatrava MJ, Castaneda S (2012) Abatacept mechanism of action: concordance with its clinical profile. Reumatologia Clinica 8: 78-83.

29. Su VC, Harrison J, Rogers C, Ensom MH (2012) Belatacept: a new biologic and its role in kidney transplantation. Ann Pharmacother 46: 57-67.

30. Vétizou M, Pitt JM1, Daillère R1, Lepage P2, Waldschmitt N3, et al. (2015) Anticancer immunotherapy by CTLA-4 blockade relies on the gut microbiota. Science 350: 1079-1084

31. Beck KE, Blansfield JA, Tran KQ, Feldman AL, Hughes MS, et al. (2006) Enterocolitis in patients with cancer after antibody blockade of cytotoxic T-lymphocyte-associated antigen 4. J Clin Oncol 24: 2283-2289.

32. Ishida Y, Agata Y, Shibahara K, Honjo T (1992) Induced expression of PD-1, a novel member of the immunoglobulin gene superfamily, upon programmed cell death. EMBO J 11: 3887-3895.

33. Freeman GJ, Long AJ, Iwai Y, Bourque K, Chernova T, et al. (2000) Engagement of the PD-1 immunoinhibitory receptor by a novel B7 family member leads to negative regulation of lymphocyte activation. J Exp Med 192: 1027-1034.

34. Dong H, Zhu G, Tamada K, Chen L (1999) B7-H1, a third member of the B7 family, co -stimulates T-cell proliferation and interleukin -10 secretion. Nat Med 5: $1365-1369$.

35. Latchman Y, Wood CR, Chernova T, Chaudhary D, Borde M, et al. (2001) PDL2 is a second ligand for PD-1 and inhibits T cell activation. Nat Immunol 2: 261-268.

36. Nishimura H, Nose M, Hiai H, Minato N, Honjo T (1999) Development of lupuslike autoimmune diseases by disruption of the PD-1 gene encoding an ITIM motif-carrying immunoreceptor. Immunity 11: 141-151.

37. Keir ME, Butte MJ, Freeman GJ, Sharpe AH (2008) PD-1 and its ligands in tolerance and immunity. Annu Rev Immunol 26: 677-704.

38. Barber DL, Wherry EJ, Masopust D, Zhu B, Allison JP, et al. (2006) Restoring function in exhausted CD8 T cells during chronic viral infection. Nature 439: 682-687.

39. Wherry EJ, Blattman JN, Murali-Krishna K, van der Most R, Ahmed R (2003) Viral persistence alters CD8 T-cell immunodominance and tissue distribution and results in distinct stages of functional impairment. J Virol 77: 4911-4927.

40. Ahmadzadeh M, Johnson LA, Heemskerk B, Wunderlich JR, Dudley ME, et al. (2009) Tumor antigen-specific CD8 T cells infiltrating the tumor express high levels of PD-1 and are functionally impaired. Blood 114: 1537-1544.

41. Zeng Z, Shi F, Zhou L, Zhang MN, Chen Y, et al. (2011) Upregulation of circulating PD-L1 / PD-1 is associated with poor post-cryoablation prognosis in patients with HBV-related hepatocellular carcinoma. PloS one 6: e23621.

42. Shi F, Shi M, Zeng Z, Qi RZ, Liu ZW, et al. (2011) PD-1 and PD-L1 upregulation promotes $\mathrm{CD} 8(+) \mathrm{T}$-cell apoptosis and postoperative recurrence in hepatocellular carcinoma patients. Int J Cancer 128: 887-896.

43. Jiang Y, Li Y, Zhu B (2015) T-cell exhaustion in the tumor microenvironment. Cell Death Dis 6: e1792.

44. Muenst S, Schaerli AR, Gao F, Däster S, Trella E, et al. (2014) Expression of programmed death ligand 1 (PD-L1) is associated with poor prognosis in human breast cancer. Breast Cancer Res Treat 146: 15-24.

45. Momtaz P, Postow MA (2014) Immunologic checkpoints in cancer therapy: focus on the programmed death-1 (PD-1) receptor pathway. Pharmgenomics Pers Med 7: 357-365.

46. Topalian SL, Hodi FS, Brahmer JR, Gettinger SN, Smith DC, et al. (2012) Safety, activity, and immune correlates of anti-PD-1 antibody in cancer. N Eng J Med 366: 2443-2454

47. Berger R, Rotem Yehudar R, Slama G, Landes S, Kneller A, et al. (2008) 
Phase I safety and pharmacokinetic study of CT-011, a humanized antibody interacting with $\mathrm{PD}-1$, in patients with advanced hematologic malignancies. Clin Cancer Res 14: 3044-3051.

48. Hamid O, Robert C, Daud A, Hodi FS, Hwu WJ, et al. (2013) Safety and tumor responses with lambrolizumab (anti - PD 0-1) in melanoma. $N$ Engl J Med 369: 134-144.

49. Brahmer JR, Tykodi SS, Chow LQ, Hwu WJ, Topalian SL, et al. (2012) Safety and activity of anti-PD-L1 antibody in patients with advanced cancer. $\mathrm{N}$ Engl J Med 366: 2455-2465

50. Powles T, Eder JP, Fine GD, Braiteh FS, Loriot Y, et al. (2014) MPDL3280A (anti-PD-L1) treatment leads to clinical activity in metastatic bladder cancer. Nature 515: 558-562.

51. Deal watch: GlaxoSmithKline and Amplimmune join forces on targeting PD (2010) Nat Rev Drug Discov 9: 754.

52. Mahoney KM, Freeman GJ, McDermott DF (2015) The Next ImmuneCheckpoint Inhibitors: PD -1 / PD-L1 Blockade in Melanoma. Clin Ther 37: 764-782.

53. Lee L, Gupta M, Sahasranaman S (2016) Immune Checkpoint inhibitors: An introduction to the next-generation cancer immunotherapy. J Clin Pharmacol 56: 157-169

54. Wolchok JD, Kluger H, Callahan MK, Postow MA, Rizvi NA, et al. (2013) Nivolumab plus ipilimumab in advanced melanoma. N Engl J Med 369: 122 133.

55. Duraiswamy J, Kaluza KM, Freeman GJ, Coukos G (2013) Dual blockade of PD-1 and CTLA-4 combined with tumor vaccine effectively restores T-cel rejection function in tumors. Cancer Res 73: 3591-3603.

56. Curran MA, Montalvo W, Yagita H, Allison JP (2010) PD-1 and CTLA-4 combination blockade expands infiltrating $T$ cells and reduces regulatory $T$ and myeloid cells within B16 melanoma tumors. Proc Natl Acad Sci U S A 107: 4275-4280.

57. Fauci JM, Straughn JM Jr, Ferrone S, Buchsbaum DJ (2012) A review of B7-H3 and B7-H4 immune molecules and their role in ovarian cancer. Gynecol Oncol 127: 420-425.

58. Woo SR, Turnis ME, Goldberg MV, Bankoti J, Selby M, et al. (2012) Immune inhibitory molecules LAG-3 and PD-1 synergistically regulate T-cell function to promote tumoral immune escape. Cancer Res 72: 917-927.

59. Goldberg MV, Drake CG (2011) LAG-3 in Cancer Immunotherapy. Curr Top Microbiol Immunol 344: 269-278.

60. Blackburn SD, Shin H, Haining WN, Zou T, Workman CJ, et al. (2009) Coregulation of CD8 + T cell exhaustion by multiple inhibitory receptors during chronic viral infection. Nat Immunol 10: 29-37.

61. Workman CJ, Vignali DA (2003) The CD4-related molecule, LAG-3 (CD223), regulates the expansion of activated T cells. Eur J Immunol 33: 970-979.

62. Huang CT, Workman CJ, Flies D, Pan X, Marson AL, et al. (2004) Role of LAG3 in regulatory T cells. Immunity $21: 503-513$.
63. Buck MD, O'Sullivan D, Pearce EL (2015) T cell metabolism drives immunity. J Exp Med 212: 1345-1360.

64. O'Sullivan D, Pearce EL (2015) Targeting T cell metabolism for therapy. Trends Immunol 36: 71-80.

65. Leone RD, Lo YC, Powell JD (2015) A2aR antagonists: Next generation checkpoint blockade for cancer immunotherapy. Comput Struct Biotechnol J 13: $265-272$.

66. Coley WB (1910) The Treatment of Inoperable Sarcoma by Bacterial Toxins (the Mixed Toxins of the Streptococcus erysipelas and the Bacillus prodigiosus) Proc R Soc Med 3: 1-48.

67. Hutloff A, Dittrich AM, Beier KC, Eljaschewitsch B, Kraft R, et al. (1999) ICOS is an inducible T-cell co-stimulator structurally and functionally related to CD28. Nature 397: 263-266.

68. Brunet JF, Denizot F, Luciani MF, Roux-Dosseto M, Suzan M, et al. (1987) A new member of the immunoglobulin superfamily--CTLA-4. Nature 328: 267-270.

69. Jin HT, Ahmed R, Okazaki T (2011) Role of PD-1 in regulating T-cell immunity. Curr Top Microbiol Immunol 350: 17-37.

70. Watanabe N, Gavrieli M, Sedy JR, Yang J, Fallarino F, et al. (2003) BTLA is a lymphocyte inhibitory receptor with similarities to CTLA-4 and PD-1. Nat Immunol 4: 670-679.

71. Nguyen LT, Ohashi PS1 (2015) Clinical blockade of PD1 and LAG3--potential mechanisms of action. Nat Rev Immunol 15: 45-56.

72. Lines JL, Sempere LF, Broughton T, Wang L, Noelle R (2014) VISTA is a nove broad- spectrum negative checkpoint regulator for cancer immunotherapy. Cancer Immunol Res 2: 510-7.

73. Curti BD, Kovacsovics Bankowski M, Morris N, Walker E, Chisholm L, et al. (2013) OX40 is a potent immune-stimulating target in late-stage cancer patients. Cancer Res 73: 7189-98.

74. Lin W, Voskens CJ, Zhang X, Schindler DG, Wood A, et al. (2008) Fc-dependent expression of CD137 on human NK cells: insights into "agonistic" effects of antiCD137 monoclonal antibodies. Blood 112: 699-707.

75. Avogadri F, Yuan J, Yang A, Schaer D, Wolchok JD (2011) Modulation of CTLA-4 and GITR for cancer immunotherapy. Curr Top Microbiol Immunol 344: 211-244.

76. Montgomery RI, Warner MS, Lum BJ, Spear PG (1996) Herpes simplex virus-1 entry into cells mediated by a novel member of the TNF/NGF receptor family. Cell 87: 427-436.

77. Anderson AC (2014) Tim-3: an emerging target in the cancer immunotherapy landscape. Cancer Immunol Res 2: 393-398.

78. Fourcade J, Sun Z, Pagliano O, Chauvin JM, Sander C, et al. (2014) PD-1 and Tim-3 regulate the expansion of tumor antigen-specific CD8 $\hat{a}^{\circ} \mathrm{T}$ cells induced by melanoma vaccines. Cancer Res 74: 1045-1055.

79. Arnett HA, Viney JL (2014) Immune modulation by butyrophilins. Nat Rev Immunol 14: 559-569. 